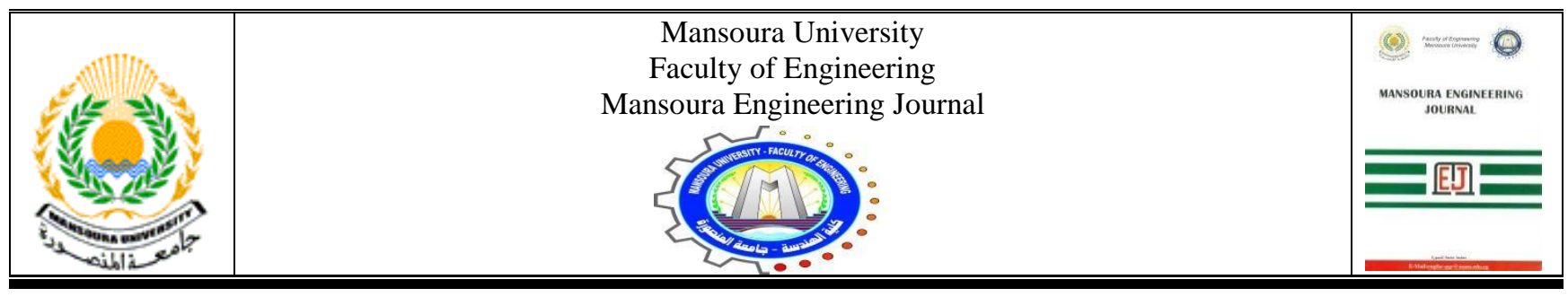

\title{
Development of Sustainable Lightweight Concrete Using C old-Bonded Lightweight Aggregates
}

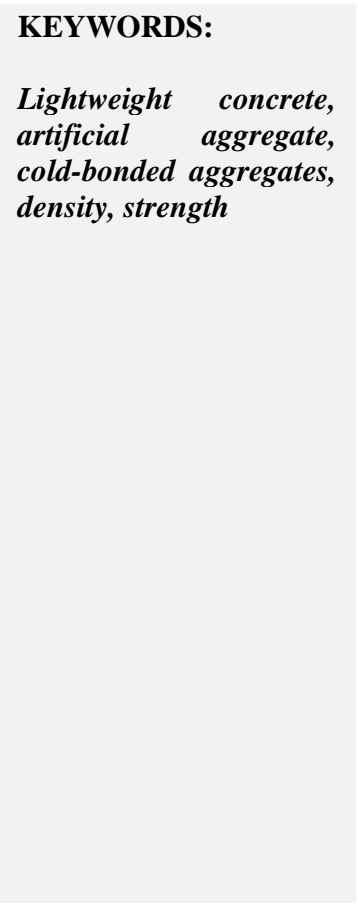

\author{
Mohamed E. El Madawy
}

\begin{abstract}
LWC) can be considered as a structural material with unique characteristics such as reduced thermal insulation and low density. However, it consumes huge amount of artificial lightweight aggregates (LWA). Artificial LWA can be manufactured using sintering method or coldbonded technique. Spite sintering method is more common due to low density of the produced LWA with appropriate mechanical characteristics, it has some economic and environmental drawbacks. Contrarily, cold-bonded technique has environmental and economic benefits due to potential lower energy consumption compared to sintering method. Nevertheless, its application still limited due to low mechanical properties as well as high density of the produced aggregate. This research presents a new method of producing sustainable coreshell artificial lightweight aggregate by using cold-bonded method. To minimize the aggregate density, expanded perlite particles with very low density was encapsulated in a cover layer made of powdered perlite, fly ash and cement. To improve mechanical characteristics of the produced aggregates, surface treatment using a mixture of microsilica and cement was applied. To compare the performance with sintered aggregates (expanded clay), several LWC mixes were prepared and tested. Mechanical properties, thermal conductivity as well as durability of LWC were measured. Scanning Electron Microscopy measurements were conducted to examine aggregate-cement matrix transition zone. The experimental results revealed that the performance of cold-bonded LWA is comparable with sintered LWA. Moreover, LWA with dry density in the range of $1200-1500 \mathrm{~kg} / \mathrm{m}^{3}$ and compressive strength of 18-25 MPa was developed using cold-bonded LWA
\end{abstract}

\section{INTRODUCTION}

$\mathrm{L}$ IGHTWEIGHT concrete (LWC) is construction material with reduced density, excellent insulation properties as well as reasonable mechanical

Received: (28 September, 2020) - Revised: (28 December, 2020) Accepted: (4 January, 2021)

Corresponding Author: Dr. Mohamed Eltantawy Elmadawy, Structural Engineering Department, Faculty of Engineering, Mansoura University, Egypt,+201016067701, (e-mail: m_eltantawy@mans.edu.eg)). properties. Due to its unique characteristics it attracts great interest for application in different types of structures [1, 2]. Compared to normal-weight concrete, it has lower mass and better thermal insulation which offer environmental, economic and technical advantages [3-6]. It can be made by totally or partially substitute normal weight aggregate with low-density aggregates (LWA) that can be used directly from natural resources or produced by technical methods [7]. Natural LWAs are limited in quantities and not available in many areas, therefore much interest is focused on the artificial LWAs. Artificial LWAs can be manufactured either by coldbonding method or using sintering of the raw materials. 
Sintering methods is more common and the produced aggregates by this technology have appropriate characteristics; high mechanical properties with low density [8]. In the sintering method, raw material is finely ground, mixed, granulated to small pellets and then sintered at temperature up to $1200{ }^{\circ} \mathrm{C}$ such as expanded glass or expanded clay $[9,10]$.

In spite of the many technical benefits of sintering technology for manufacturing LWA, it has some disadvantages such as intensive energy consumption as well as harmful environmental impacts which increase the sustainability problems of LWC [11]. In comparison, coldbonding technology is more environmentally friendly and has lower energy consumption. In addition, this method can be considered as a beneficial technology to consume huge amount of by-product and waste materials in the manufacturing process [13-14]. Several researches have been carried out to investigate the effect of cold-bonded LWAs on the characteristics of LWAC [14-18]. The main drawbacks of utilization cold-bonded aggregate are its increased density and the low crushing strength compared to sintered LWAs [19]. However, to enhance the performance of cold bonded aggregates, dry density should be reduced, and crushing strength should be increased [20].

Surface treatment of cold-bonded aggregates is considered as one of the effective methods to improve the performance of the aggregates [11]. The high water absorption of cold-bonded aggregate is considered as one of the main problems hindering the wide application in construction field [19]. Gesoglu et al. used a solution of water glass and silica fume slurry to treat the surface of cold-bonded aggregate. They found that the treated aggregates have lower water absorption and better crushing strength than untreated aggregates [21, 22]. Hwang et al. sprayed an alkaline solution on the aggregate surface and found that the crushing strength is improved by about $20 \%$ while the water absorption was reduced by $25 \%$ [20]. In addition, incorporation of mineral additives can improve the produced aggregates properties [23]. The reaction between the pozzolanic materials with calcium hydroxide improves the mechanical properties and reduces the porosity of the produced cold-bonded aggregates [24].

This study aims to develop cold-bonded aggregate with appropriate properties which are comparable to sintered LWA. Cold-bonded technology was adopted to produce core-shell LWA using cement, fly ash as well as expanded perlite powder as a shell of the particles to reduce particle density.
The core material of the aggregate was expanded perlite with low density to minimize the density of the produced aggregate. Moreover, to improve mechanical properties, the aggregate surface was treated using a mixture of cement and silica fume. At the end several LWAC mixes were produced using developed LWA and sintered LWA (Liapor, expanded clay) to compare their influences on concrete properties.

\section{MATERIALS}

In this investigation, the experimental work was carried out in two steps: the first was to optimize and develop coreshell cold-bonded LWAs. The second step was to prepare, produce and compare between the properties of LWC mixes using cold-bonded and sintered LWAs.

\section{A. Production of cold-bonded lightweight aggregates}

In this part, a granulator (pelletizer) dish with a radius of $200 \mathrm{~mm}$ and height of $100 \mathrm{~mm}$ has been used and adopted with granulation speed and angle of $30 \mathrm{rpm}$ and $35^{\circ}$ respectively. In the manufacturing process, expanded perlite was added first to the granular disc (core) as can be seen in Figure 1. Then the disc was working with the specified speed and angle and then water and a mixture of Ordinary Portland cement, CEMI $42.5 \mathrm{R}$, class $\mathrm{f}$ fly ash and fine powdered perlite $(<0.125 \mathrm{~mm})$ with volumetric ratios of 18,49 , and 33 $\%$ were added to encapsulate the perlite particles (shell). The size of the produced aggregates particles depends mainly on the initial size of the expanded perlite in the core. In this investigation, expanded perlite particles with size of 1-4 mm was used in the core to produce cold-bonded aggregate with size of 2-8 $\mathrm{mm}$ respectively. Table 1 shows physical properties and chemical characteristics of the fine materials. Chemical composition of fine materials have been measured using X-ray fluorescence analysis (XRF, TU Berlin Germany). Figure 2 shows the particle size distribution of the fine materials. After manufacturing, the fresh lightweight aggregate pellets were taken out from the pelletizer and stored in for 24 hours at laboratory conditions. Then, in order to improve the strength of the manufactured aggregates, a cement-microsilica mixture were used to cover the surface of the produced aggregate. At the end, the hardened pellets were cured under controlled relative humidity (RH) of $99 \%$ and temperature of $21 \pm 1^{\circ} \mathrm{C}$.
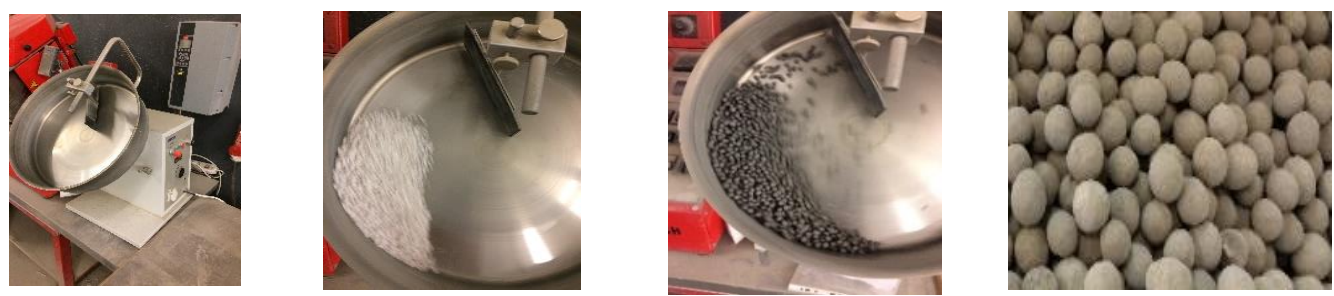

Fig. 1: Production process of cold-bonded aggregate using granulator dish 
TABLE 1

CHEMICAL COMPOSITION AND PHYSICAL PROPERTIES OF FINE MATERIALS

\begin{tabular}{|c|c|c|c|c|c|c|c|c|c|c|c|}
\hline Material & $\mathrm{CaO}$ & $\mathrm{SiO} 2$ & $\mathrm{Al}_{2} \mathbf{O}_{3}$ & $\mathrm{Fe}_{2} \mathrm{O}_{3}$ & MgO & $\mathrm{Na}_{2} \mathrm{O}$ & $\mathrm{K}_{2} \mathrm{O}$ & $\mathrm{SO}_{3}$ & $\begin{array}{l}\text { Loss on } \\
\text { ignition }\end{array}$ & \multirow[t]{2}{*}{$\begin{array}{c}\text { Specific } \\
\text { gravity }\end{array}$} & \multirow{2}{*}{$\begin{array}{l}\text { Surface area } \\
\left(\mathrm{m}^{2} / \mathrm{kg}\right)\end{array}$} \\
\hline & \multicolumn{9}{|c|}{ Mass \% } & & \\
\hline Cement & \begin{tabular}{|l|}
64.19 \\
\end{tabular} & 18.7 & 5.09 & 3.2 & 1.7 & 0.11 & 0.8 & 3.06 & 3.15 & 3.12 & 350 \\
\hline Fly ash & 4.39 & 55.6 & 25.58 & 6.6 & 1.8 & 0.79 & 1.8 & 0.82 & 2.52 & 2.35 & 287.7 \\
\hline Silica fume & 0.40 & 98.5 & 0.3 & 0.01 & \begin{tabular}{|l|}
0.1 \\
\end{tabular} & 0.15 & 0.4 & \begin{tabular}{|l|}
0.14 \\
\end{tabular} & 0.74 & 2.21 & 20000 \\
\hline Perlite powder & 0.89 & 76.8 & 11.27 & 0.8 & 0.2 & 3.7 & 3.5 & $\mid 1.72$ & $\mid 1.12$ & $\mid 2.39$ & 410 \\
\hline
\end{tabular}

TABLE 2

PHYSICAL PROPERTIES OF THE USED AGGREGATES

\begin{tabular}{l||l||l||l||l}
\multicolumn{1}{c|}{ Type of aggregate } & \multicolumn{1}{c||}{ Size $(\mathbf{m m})$} & \multicolumn{1}{c||}{ Shape } & Particle density $\left(\mathbf{k g} / \mathbf{m}^{\mathbf{3}}\right)$ & Water absorption (wt. \%) \\
\hline natural Sand & $0-2$ & Rounded & 2620 & 1.4 \\
\hline Lightweight sand & $0-2$ & Crushed & 1770 & 30 \\
\hline Expanded clay (Liapor) & $2-8$ & rounded & 540 & 18
\end{tabular}

TABLE 3

CHARACTERISTICS OF THE MANUFACTURED LIGHTWEIGHT AGGREGATE USING COLD-BONDED METHOD

\begin{tabular}{l||l||l||l||l}
\multicolumn{1}{c||}{} & Particle density & apparent density & Absorption $(\mathbf{2 4}$ hours) & Strength (crushing) \\
\cline { 2 - 3 } & $\mathrm{t} / \mathrm{m}^{3}$ & $\mathrm{~kg} / \mathrm{m}^{3}$ & Mass \% & $\mathrm{N} / \mathrm{mm}^{2}$ \\
\hline Without treatment & 0.97 & 550 & 45 & 3.12 \\
\hline Slurry-treated & 1.00 & 542 & 43 & 2.78 \\
\hline Powdered-treated & 1.12 & 609 & 33 & 3.56
\end{tabular}

TABLE 4

COMPOSITION OF DIFFERENT LWC MIXES (KG/M³)

\begin{tabular}{|c|c|c|c|c|c|c|}
\hline \multirow{2}{*}{$\begin{array}{l}\text { Group } \\
\text { No. }\end{array}$} & \multicolumn{3}{|l|}{1} & \multicolumn{3}{|l|}{2} \\
\hline & $\mathrm{C} 1$ & $\mathrm{C} 2$ & $\mathrm{C} 3$ & $\mathrm{C} 4$ & $\mathrm{C} 5$ & C6 \\
\hline $\mathbf{w} / \mathbf{b}$ & 0.36 & 0.36 & 0.36 & 0.36 & 0.36 & 0.36 \\
\hline Silica fume & 45 & 45 & 45 & 45 & 45 & 45 \\
\hline Cement & 405 & 405 & 405 & 405 & 405 & 405 \\
\hline Water & 162 & 162 & 162 & 162 & 162 & 162 \\
\hline Superplasticizer & 4.4 & 4.4 & 4.4 & 4.4 & 4.4 & 4.4 \\
\hline Stabilizer & 0.4 & 0.4 & 0.4 & 0.4 & 0.4 & 0.4 \\
\hline Liapor 2-8 & 289 & - & & 289 & & \\
\hline NACA 2-8 & - & 576 & & - & 576 & \\
\hline STCA 2-8 & - & & 599 & - & & 599 \\
\hline Liapor Sand 0-2 & - & & - & 365 & 365 & 365 \\
\hline Natural Sand 0-2 & 593 & 593 & 593 & - & - & - \\
\hline
\end{tabular}

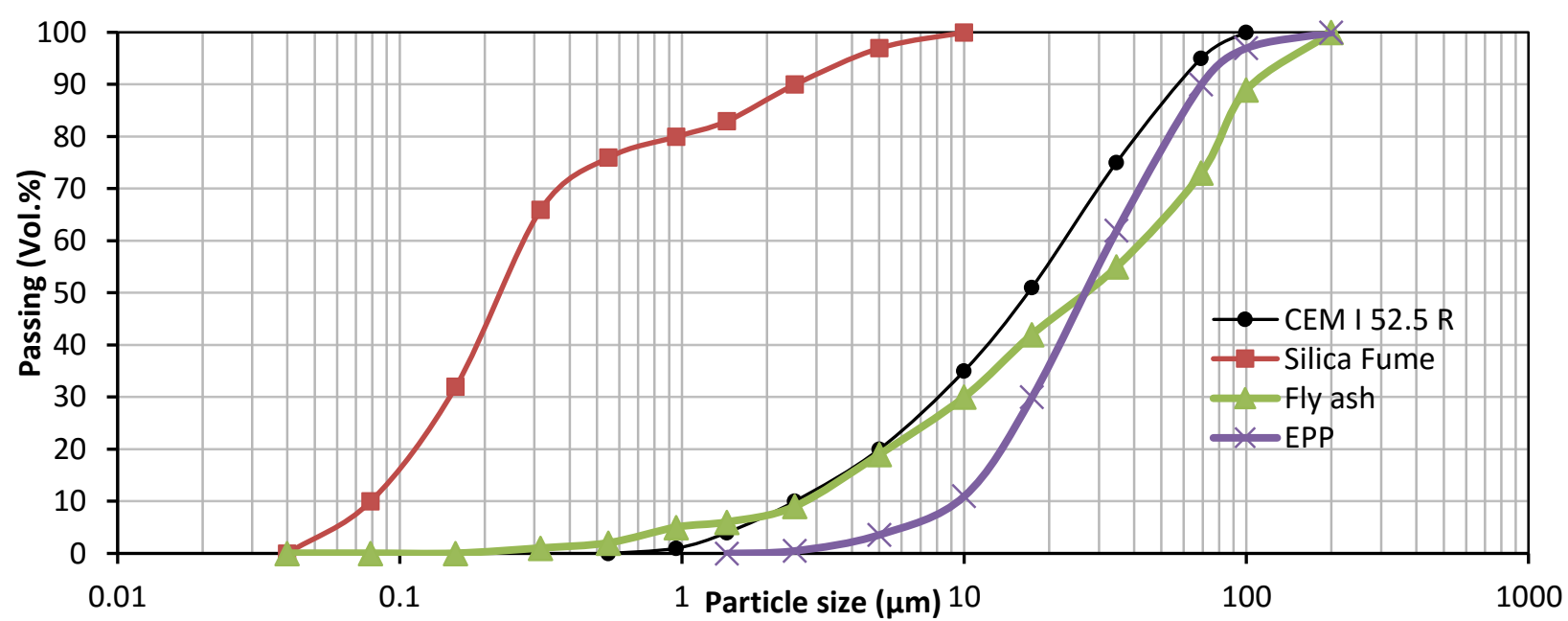

Fig 2: Particle size distribution of fine materials 


\section{B. Surface treatment of LWA}

As described previously, manufactured cold-bonded aggregates composed of internal core which is the expanded perlite particle as well as the shell cover which consists of cement, class $\mathrm{F}$ fly ash and expanded fine perlite powder as can be seen in Figure 4. After pelletization process, the pellets were stored in for 24 hours at $21^{\circ}$ and $99 \%$ relative humidity. In addition, the high porosity of aggregate surface has a negative influence of concrete durability [25]. As mentioned in the other studies, mechanical properties of LWA can be improved and water absorption can be significantly decreased by applying surface treatment [26]. In this investigation, a mixture of cement and silica fume was used to form a thin layer on the surface of manufactured aggregates as presented in Figure 5. Therefore, surface treatment process was applied on the fresh pellets either by spreading a powder mixture of cement and silica fume or by using the same mixture $(90 \%$ cement+10\% SF and w/b of 1.2) in slurry status.

\section{Production of $L W C$}

In this investigation, different LWC mixes were produced using CEM I 42.5R and silica fume (SF) as binders with a ratio for water-binder of 0.36 . A water reducing admixture, Polycarboxylic ether, PCE (Sika Viscocrete 2014) with a specific density of 1.07 was used to achieve a reasonable consistency. Viscosity enhancing admixture (Stabilizer) provided by Sika was used to improve the stability of the fresh mixture and reduce the probability of segregation and bleeding. Six different mixes have been planned and examined with total cementitious materials quantity of $450 \mathrm{~kg} / \mathrm{m}^{3}(90 \%$ cement and $10 \%$ microsilica). Two types of sand were used; lightweight sand (Liapor sand) and natural sand. Coarse aggregates with maximum size of $8 \mathrm{~mm}$ were used in different conditions; in normal conditions without surface treatment (Normal artificial cold-bonded aggregate, NACA) and surface treated cold-bonded aggregate (STCA). In addition, expanded clay aggregates available in the market (Liapor) was used to compare its performance with the developed cold-bonded aggregate. Table 2 presents the physical properties of the used aggregates. Lightweight aggregate absorbs high amount of water due to its high porosity and the connectivity of the pores, therefore, it can be used in concrete at saturated with surface dry conditions (SSD) to avoid the negative effect of absorption on properties of concrete in fresh status. To avoid the crushing of aggregate particles during the mixing process, the following mixing procedures were carried out: (1) sand and cement were first dry mixed until they were thoroughly blended; (2) superplasticizer and water were added and the mixture was mixed until achieve of homogeneity; (3) lastly, coarse aggregate were added and mixed until a homogeneous concrete mixture was achieved. The fresh concrete was casted into cube molds $100 \times 100 \times 100 \mathrm{~mm}^{3}$ and covered with a plastic foil to prevent water loss due to evaporation. All samples were demolded after one day and stored in controlled curing chamber with relative humidity of $99 \%$ and temperature of $21 \pm 1{ }^{\circ} \mathrm{C}$ till testing.

\section{TEST METHODS}

\section{A. Tests on cold-bonded lightweight aggregates}

Several tests have been performed on cold-bonded aggregates to evaluate the effect of surface treatment on manufactured aggregates properties. These tests include water absorption, dry particle density in accordance with EN 1097-6. Loose density was determined according to EN 1097-3. The bulk crushing strength of the produced aggregate was investigated based on EN 13055 [16]. It was performed at age of 28 days. The shape and inner structure of cold-bonded aggregates has been investigated using light microscopy.

\section{B. Tests for lightweight aggregate concrete}

Characteristics of fresh concrete as well as hardened concrete have been measured to evaluate and compare the performance of cold-bonded aggregate and expanded clay aggregates. In the fresh status, consistency of concrete was determined according to EN 12350-5, by measuring the spread flow diameter. For hardened concrete, dry density and compressive strength have been measured in accordance with EN 12390- part 7 and the standards EN 12390-part 3 respectively. Thermal conductivity of concrete has been determined using Hot Disk device in accordance with ISO 22007-2. In addition, the sorptivity of concrete as an indicator for concrete durability was measured according to EN ISO 15148. Moreover, scanning electron microscopy observations have been utilized to investigate the properties of interfacial zone between cement matrix and aggregates.

\section{RESULTS AND DISCUSSIONS}

The experimental results of cold-bonded LWA revealed that the crushing strength of the produced aggregate is 3.12 $\mathrm{N} / \mathrm{mm}^{2}$ with particle density of $0.97 \mathrm{t} / \mathrm{m}^{3}$ which is comparable to other researchers [27]. Incorporation of expanded particles reduced the particle density, while the use of the perlite powder improved the crushing strength due to its pozzolanic reactivity and high surface area. On the other hand, the effect of surface treatment on the characteristics of artificial coldbonded aggregates has been evaluated by measuring physical and mechanical characteristics of lightweight aggregates at age of 28 days. The results showed that with surface treatment using coating method (powder), a crushing strength of 3.56 can be achieved with a bit increase in the particle density of about $13 \%$ compared to the non-treated aggregates. Moreover, the water absorption was significantly decreased by applying coating method. Treatment of aggregate with powdered mixture of cement and silica fume is more efficient than slurry mixture: strength is higher by about $89 \%$ and water absorption was lower by about $24 \%$. This can be attributed to better coating of the powder mixture to cover the aggregate surface and formation of thin film which decreases the absorption degree and increase the crushing strength significantly. Silica fume addition on the surface of aggregate densify the pore structure due to its filler and pozzolanic effects compared to aggregate without surface treatment. 

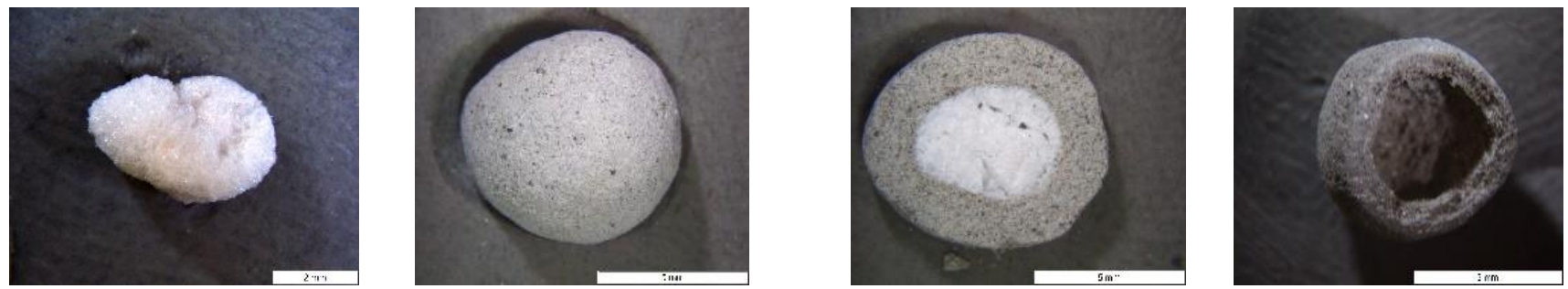

Fig. 3. Microscope images of LWAs (a) perlite particle, (b) hardened pellet, (c) cover matrix, and (d) section of pellet

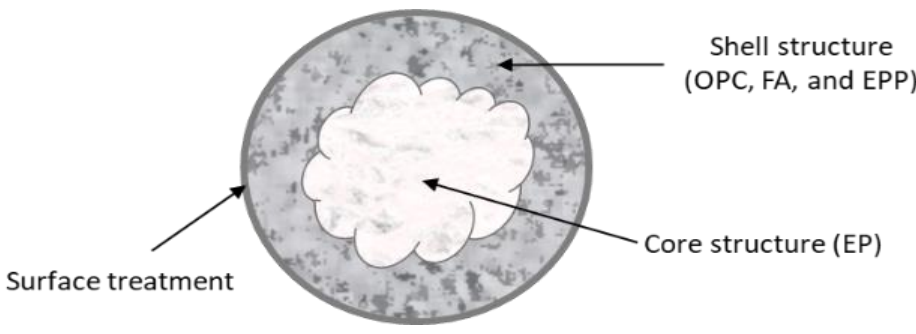

Fig. 4. Cross section of lightweight aggregate pellet

\begin{tabular}{|c|c|c|c|}
\hline $\begin{array}{c}\text { Expanded clay } \\
\text { aggregate }\end{array}$ & $\begin{array}{c}\text { Non-treated } \\
\text { aggregate }\end{array}$ & $\begin{array}{c}\text { Aggregate with slurry } \\
\text { treatment }\end{array}$ & $\begin{array}{c}\text { Aggregate with coating } \\
\text { treatment }\end{array}$ \\
\hline & & & \\
& & & \\
\hline $5 \mathrm{~mm}$ & $55 \mathrm{~mm}$ & $5 \mathrm{~mm}$ \\
\hline \\
\hline 5
\end{tabular}

Fig. 5: Comparison between expanded clay, treated and untreated cold-bonded aggregates

\section{A. Mechanical and physical Properties of $L W C$}

In this research work, six different LWC mixes were prepared and tested. Table 4 shows the composition of all mixes. The properties of lightweight concrete (LWC) have been evaluated in fresh status by measuring the consistency as described in EN 206 part 1. All mixes achieved a slump flow diameter in the range of $420-450 \mathrm{~mm}$ as planned. For hardened LWC, several tests were performed to measure mechanical properties as well as concrete durability. As can be seen from table 4 , three different types of coarse aggregates have been used: expanded clay (Liapor), untreated coldbonded aggregates (NACA) and treated cold-bonded aggregates (STCA) as well as two types of fine aggregates with size of 0-2 mm; natural sand and lightweight sand. As can be seen from Figures 6 and 7, mixes with natural sand; $\mathrm{C} 1, \mathrm{C} 2$, and $\mathrm{C} 3$, have higher density than mixes prepared with lightweight sand. In addition, strength of lightweight concretes made with normal-weight sand was larger than mixes with Liapor sand. For the same type of lightweight aggregate, mixes C3 and C6 prepared with surface-treated cold-bonded aggregate have higher strength than other mixes prepared with expanded clay or untreated cold-bonded aggregates. At the same time, these two mixes have the highest densities. To compare the performance of various types of aggregates, both strength as well as oven dry density should be taken into consideration. Therefore, in this investigation a strength/density ratio was used as a parameter to compare the efficiency of different types of aggregates (Figure 8). It is clear from strength/density ratio values that, coated coldbonded lightweight aggregates has the better performance than uncoated one and even better than expanded clay aggregates. Replacement of expanded clay (C1) with surface treated coldbonded lightweight aggregate (C3) resulted in an increase in strength/density of lightweight concrete by about $7 \%$. Similarly, mix C6 prepared with STCA and lightweight sand exhibited higher strength/density ratio than mix $\mathrm{C} 4$ prepared with expanded clay by about $12 \%$. This improvement can be explained by the high crushing strength of STCA aggregate compared to non-treated aggregates. 


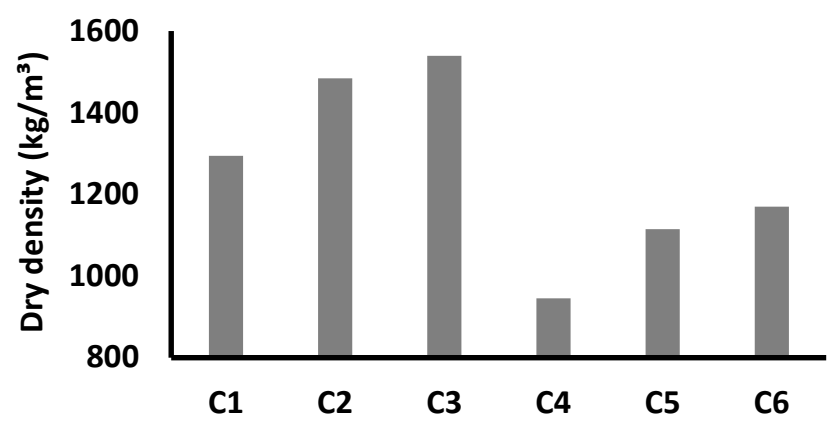

Fig. 6: Experimental results of dry density of LWC

Thermal conductivity is one of the most important properties of lightweight concrete, particularly for thermalinsulation purposes. In this investigation, hot Disk was employed to determine thermal characteristics of lightweight concretes as shown in table 5 . As can be obviously noticed, thermal conductivity is a property which depends mainly on material density rather than other characteristics. It increased with increasing the dry density of LWC (mixes C1, C2, C3). Mixes prepared with lightweight sand have lower thermal conductivity than other mixes. At the same density class the influence of the mixture composition on thermal conductivity is very limited.

\section{B. Durability and microstructure of $L W C$}

In this investigation, water absorption coefficient is used as an indicator for lightweight concrete durability. Figure 9 presents the measured results of water absorption coefficient of different LWC mixes. It is obvious from the Figure that mixes with natural sand $(\mathrm{C} 1, \mathrm{C} 2, \mathrm{C} 3)$ have lower water absorption than mixes with lightweight sand (C4, C5, C6) due to the high porosity of Liapor sand. For mixtures prepared with the same fine aggregates, non-treated coarse aggregate has negative effects on water absorption in comparison with other types. The open pores on the surface of NACA increases the penetration of water into the aggregate particles and therefore increased the absorption of concrete. In contrast, incorporation of STCA decreased the absorption of concrete due to covering the aggregate surface with cement-silica mixture which refine the pores on the surface and break its connectivity. Moreover, this type of aggregate densify the transition zone and improve its characteristics. These effects resulted in decreasing the water absorption of LWC to be very close to that of mixes prepared with expanded clay (Liapor). The images of SEM of concrete samples at age of 28 days which presented in Figure 10 confirmed the refinement of the interfacial transition zone in case of STCA. The thickness of the ITZ is decreased in case of treated aggregate due to the participation of the coating mixture in the reaction of cement in the matrix. This can be clearly observed from Figure $10 \mathrm{a}$.

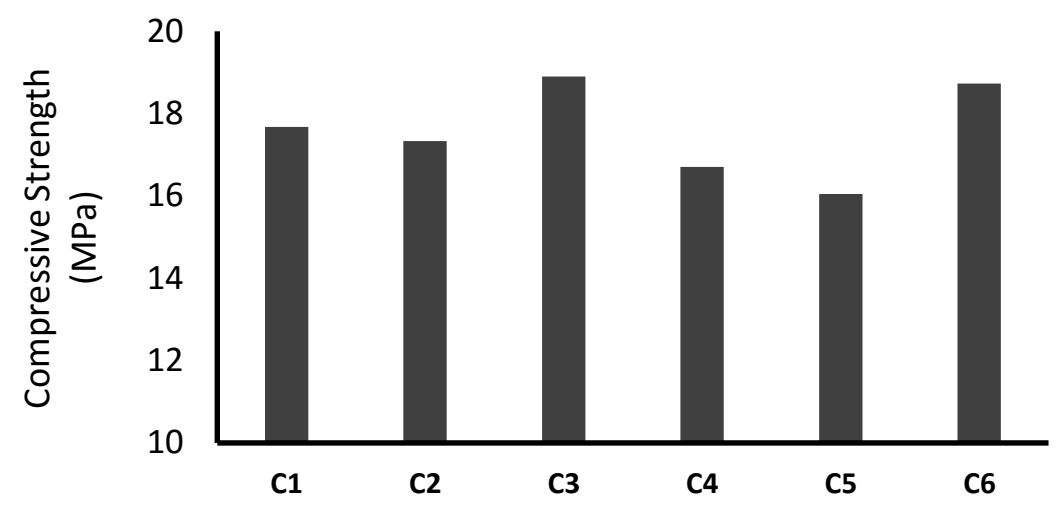

Fig. 7: Experimental results of Compressive strength of LWC

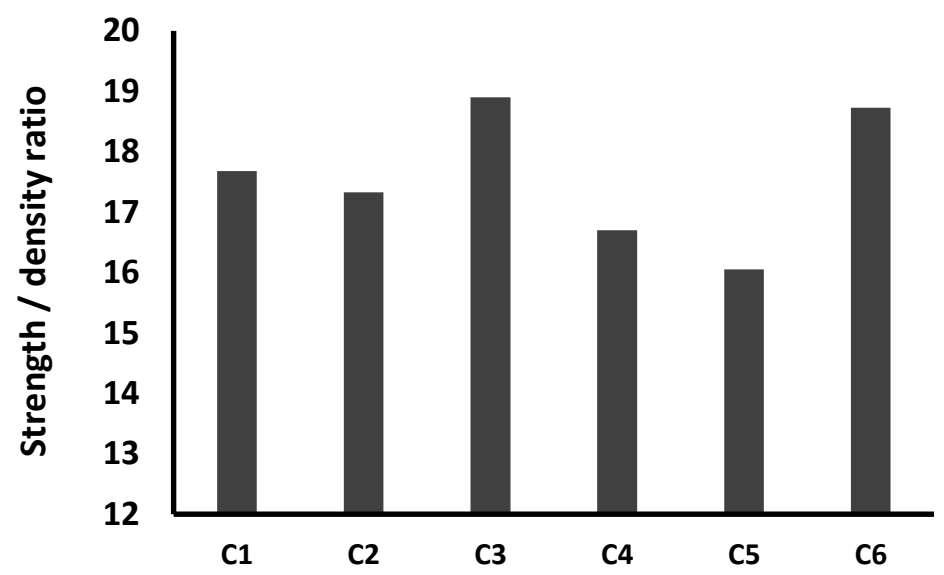

Figure 8: Strength/ density ratio of LWC mixes 
Table 5

Thermal conductivity results of different LWC mixes

\begin{tabular}{|c|c|c|}
\hline \multirow{3}{*}{ Series } & & Thermal conductivity \\
\hline & & $(\mathbf{W} / \mathbf{m} . \mathbf{K})$ \\
\hline & $\mathrm{C} 1$ & 0.4578 \\
\hline \multirow[t]{3}{*}{1} & $\mathrm{C} 2$ & 0.6364 \\
\hline & $\mathrm{C} 3$ & 0.6660 \\
\hline & $\mathrm{C} 4$ & 0.3000 \\
\hline \multirow[t]{2}{*}{2} & $\mathrm{C} 5$ & 0.3169 \\
\hline & C6 & 0.3415 \\
\hline
\end{tabular}

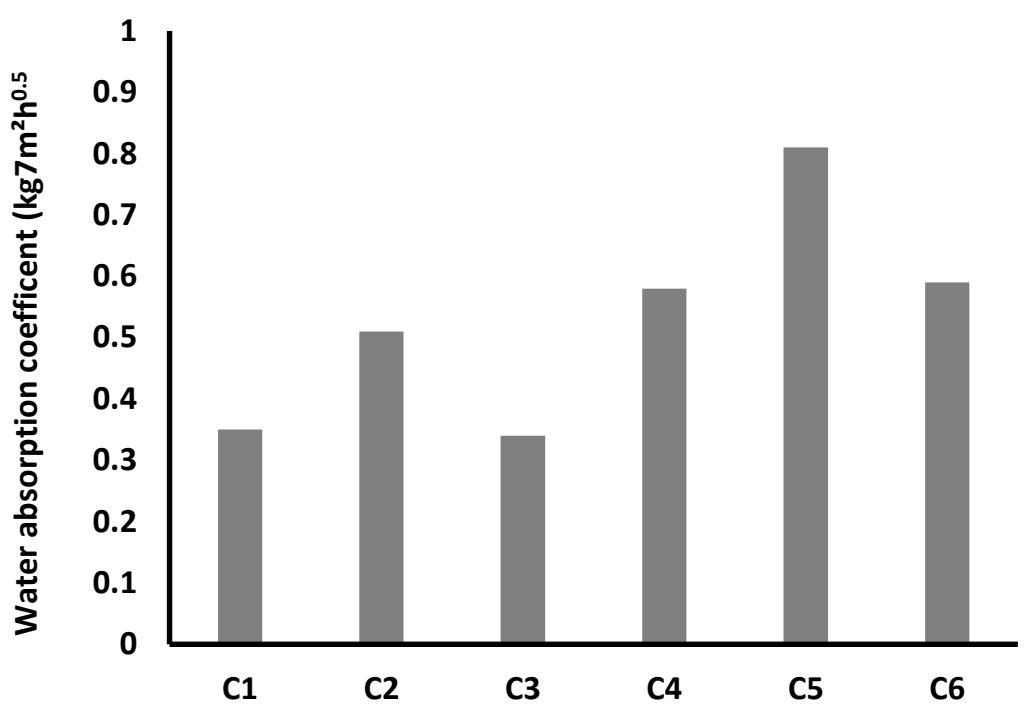

Fig.9: Water absorption coefficient o LWC mixes
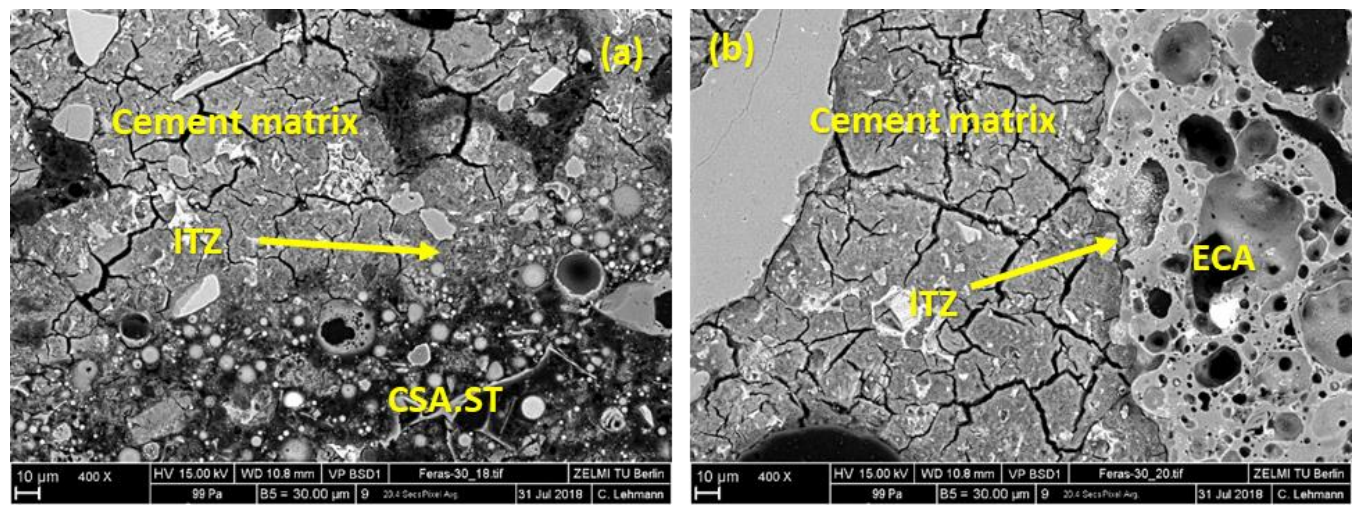

Fig. 10. Scanning electron microscopy of transition zone of concrete at age of 28 days: (a) treated aggregates, (b) Liapor

\section{Conclusion}

The following conclusions can be drawn based on the obtained experimental results:

- This study shows a new method for producing sustainable cold-bonded LWAs, with a core-shell structure that satisfy both, a decreased particle density and appropriate mechanical properties.

- Cold-bonded aggregate with particle density of $0.99 \mathrm{t} / \mathrm{m}^{3}$ and crushing strength of $3.12 \mathrm{MPa}$ has been developed which is in the same level of sintered lightweight aggregates. The inclusion of expanded perlite as a core material decreased the particle density without deteriorating the strength.

- Surface treatment improved strength/density ratio and reduced water absorption of aggregate as well. It fills the pores on the aggregate surface and improve the crushing strength of aggregate due to the filler and pozzolanic effects of silica fume

- Mechanical properties as well as durability of LWC manufactured with coated cold-bonded aggregates are comparable to LWC made with expanded clay aggregates (Liapor). 
- LWC with compressive strength of 18-29 MPa has been produced using the developed cold-bonded aggregates due to its influence on densifying the transition zone and improve the bond with the cement matrix.

- Water absorption coefficient of concrete manufactured using cold-bonded aggregates is in the same range of that made with expanded clay. Treatment of aggregate surface refine the pores and break their connectivity which improve concrete durability.

- This investigation proves the possibility of manufacturing eco-friendly artificial lightweight concrete with reduced energy consumption and minimal harmful influences on concrete properties.

\section{REFERENCES}

[1] M. Aslam, P. Shafigh, M.Z. Jumaat, M. Lachemi, Benefits of using blended waste coarse lightweight aggregates in structural lightweight aggregate concrete, J. Clean. Prod. 119 (2016) 108-117.

[2] T.Y. Lo, W.C. Tang, H.Z. Cui, The effects of aggregate properties on lightweight concrete, Build. Environ. 42 (2007) 3025-3029.

[3] [ G. Baykal, A.G. Döven, Utilization of fly ash by pelletization process; theory, application areas and research results, Resour. Conserv. Recycl. 30 (2000) 59-77.

[4] G. Joseph, K. Ramamurthy, Influence of fly ash on strength and sorption characteristics of cold-bonded doi:10.1016/j.conbuildmat.2008.09.018.

[5] Q.L. Yu, P. Spiesz, H.J.H. Brouwers, Ultra-lightweight concrete: Conceptual design and performance evaluation, Cem. Concr. Compos. 61 (2015) 18-28..

[6] T.Y. Lo, H.Z. Cui, Z.G. Li, Influence of aggregate pre-wetting and fly ash on mechanical properties of lightweight concrete, Waste Manag. 24 (2004) 333-338.

[7] N.A. Libre, M. Shekarchi, M. Mahoutian, P. Soroushian, Mechanical properties of hybrid fiber reinforced lightweight aggregate concrete made with natural pumice, Constr. Build. Mater. 25 (2011) 2458-2464.

[8] L. Korat, V. Ducman, A. Legat, B. Mirtič, Characterisation of the poreforming process in lightweight aggregate based on silica sludge by means of X-ray micro-tomography (micro-CT) and mercury intrusion porosimetry (MIP), Ceram. Int. 39 (2013) 6997-7005.

[9] Bamdad Ayati, Veronica Ferrandiz-Mas, Darryl Newport and Christopher Cheeseman, "Use of fly ash in the manufacture of lightweight aggregate", Construction and Building Materials 162 (2018), 124-131.

[10] Tommy Yiu Lo, Hongzhi Cui, Shazim Ali Memon, and Takafumi Noguchi, "Manufacturing of sintered lightweight aggregate using highcarbon fly ash and its effect on the mechanical properties and microstructure of concrete", Journal of Cleaner Production 112 (2016) 753-762.

[11] Feras Tajra, Mohamed Abd Elrahman, Dietmar Stephan, "The production and properties of cold-bonded aggregate and its application in concrete: A review", Construction and Building Materials 225 (2019) $29-43$.

[12] E. Güneyisi, M. Gesog^lu, Ö. Pürsünlü, K. Mermerdas, "Durability aspect of concretes composed of cold bonded and sintered fly ash lightweight aggregates", Compos. B Eng. 53 (2013) 258-266,

[13] P. Gomathi, A. Sivakumar, "Accelerated curing effects on the mechanical performance of cold bonded and sintered fly ash aggregate concrete", Construction and Building Materials 77 (2015) 276-287.

[14] P. Tang, M.V.A. Florea, H.J.H. Brouwers, "Employing cold bonded pelletization to produce lightweight aggregates from incineration fine bottom ash", J. Cleaner Production 165 (2017) 1371-1384.

[15] M. Gesoĝlu, E. Güneyisi, S.F. Mahmood, H. öznur öz, K. Mermerdaş, "Recycling ground granulated blast furnace slag as cold bonded artificial aggregate partially used in self-compacting concrete", J. Hazard. Mater. 235-236 (2012) 352-358.

[16] J. Thomas, B. Harilal, "Properties of cold bonded quarry dust coarse aggregates and its use in concrete", Cement and Concrete. Composites $62(2015) 67-75$
[17] H. Chao-Lung, B. Le Anh-Tuan, C. Chun-Tsun, "Effect of rice husk ash on the strength and durability characteristics of concrete", Constr. Build. Mater. 25 (2011) 3768-3772.

[18] N.U. Kockal, T. Ozturan, "Strength and elastic properties of structural lightweight concretes", Mater. Des. 32 (2011) 2396-2403.

[19] O. Sengul, S. Azizi, F. Karaosmanoglu, M.A. Tasdemir, "Effect of expanded perlite on the mechanical properties and thermal conductivity of lightweight concrete", Energy and Buildings. 43 (2011) 671-676.

[20] F. Colangelo, F. Messina, R. Cioffi, "Recycling of MSWI fly ash by means of cementitious double step cold bonding pelletization: technological assessment for the production of lightweight artificial aggregates", J. Hazard. Mater. 299 (2015) 181-191.

[21] M. Gesoğlu, T. Özturan, E. Güneyisi, "Effects of fly ash properties on characteristics of cold-bonded fly ash lightweight aggregates", Construction and Building Matererials21 (2007) 1869-1878,

[22] M. Gesoğlu, T. Özturan, E. Güneyisi, "Effects of cold-bonded fly ash aggregate properties on the shrinkage cracking of lightweight concretes", Cement and. Concrete. Composites. 28 (2006) 598-605,

[23] K.I. Harikrishnan, K. Ramamurthy, "Influence of pelletization process on the properties of fly ash aggregates", Waste Management. 26 (2006) $846-852$.

[24] J. Thomas, B. Harilal, "Properties of cold bonded quarry dust coarse aggregatesvand its use in concrete", Cement and Concrete Composites 62 (2015) 67-75,

[25] O. Sengul, S. Azizi, F. Karaosmanoglu, M.A. Tasdemir, "Effect of expanded perlite on the mechanical properties and thermal conductivity of lightweight concrete", Energy Build. 43 (2011) 671-676.

[26] O. Youssf, R. Hassanli, J.E. Mills, M. Abd Elrahman, "An experimental investigation of the mechanical performance and structural application of LECA-Rubcrete", Construction and Building Materials 175 (2018) 239-253.

[27] F. Colangelo, R. Cioffi, "Use of cement kiln dust, blast furnace slag and marble sludge in the manufacture of sustainable artificial aggregates by means of cold bonding pelletization", Materials (Basel). 6 (2013) 31393159 .

Title Arabic:

\section{تطوير خرسانة خفيفة مستدامة باستخدام الركام الخفيف المصنع بطريقة الترابط علي البارد}

\section{Arabic Abstract:}

يمكن اعتبار الخرسانة الخفيفة علي أنها مادة ذات خواص مميزة مثل العزل

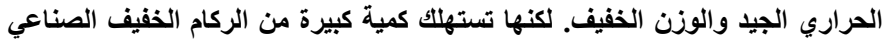

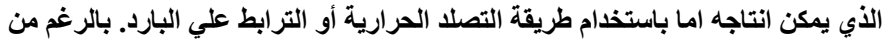

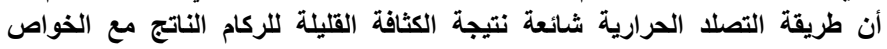

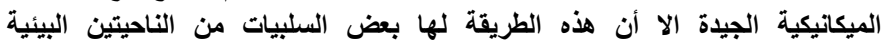

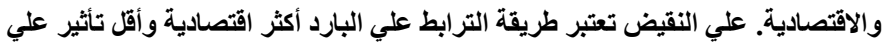

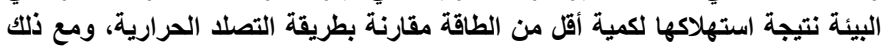

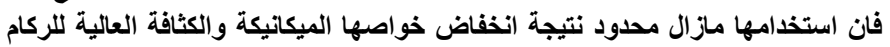

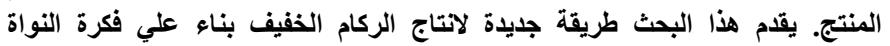

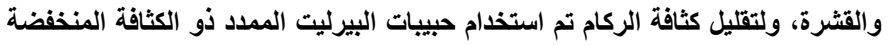

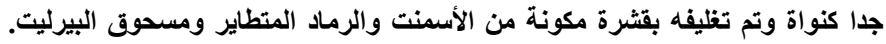

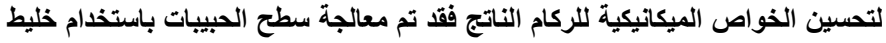

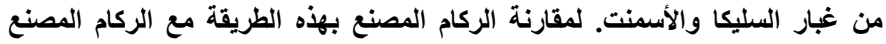

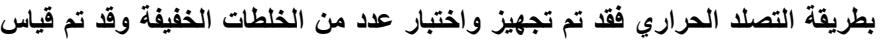

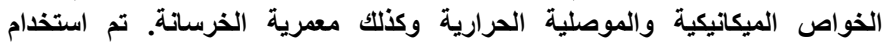

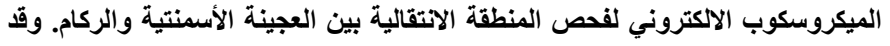

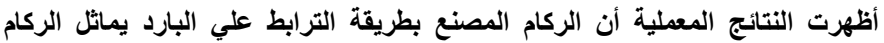

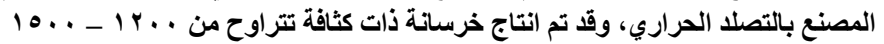

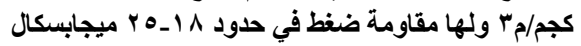

